\title{
UM DEBATE NO CAMPO DA EDUCAÇÃO AMBIENTAL SOBRE A PATRIMONIALIZAÇÃO DE VEÍCULOS NA PRAIA DO CASSINO, RIO GRANDE (RS)
}

Felipe Nóbrega Ferreira ${ }^{1}$ José Vicente de Freitas ${ }^{2}$

Gabriel Ferreira da Silva ${ }^{3}$

Resumo: O presente estudo se propõe a realizar uma análise qualitativa sobre o caso de patrimonialização do uso de veículos automotores na faixa costeira do Balneário Cassino, cidade de Rio Grande (RS) sob a perspectiva da Educação Ambiental. Partimos primeiro de um resgate histórico interpretativo dessa prática, seguido de uma análise do processo legal que culminou na aprovação da lei que transformou em Patrimônio da Cultura Imaterial o uso de carros na praia em 2017, bem como apresentamos as legislações pertinentes ao assunto do âmbito federal até o municipal, atentando-se às contradições existentes nos diferentes dispositivos legais que atravessam o tema. Em um segundo momento, nos debruçamos sobre os impactos ecossistêmicos que tal iniciativa traz à biodiversidade desse local, elencando um conjunto de riscos ambientais que estão em jogo. Por fim, apresentamos algumas alternativas que surgem do campo da Educação Ambiental que podem mediar uma nova postura ética no que tange ao uso de veículos na faixa costeira dessa praia.

Palavras-chave: Patrimonialização Costeira; Educação Ambiental; Impactos ambientais; Praia do Cassino.

\footnotetext{
${ }^{1}$ Universidade Federal do Rio Grande (FURG). E-mail: ffnobregaea@gmail.com

2 Universidade Federal do Rio Grande (FURG). E-mail: jvfreitas45@gmail.com

3 Universidade Federal do Rio Grande (FURG). E-mail: gbr.s.ferro@gmail.com
}

Revbea, São Paulo, V. 14, No 1: 245-262, 2019.

revista brasileira educação ambiental 


\section{Introdução}

Ao chegarmos ao Balneário Cassino, localizado na cidade de Rio Grande/RS, nos deparamos com uma situação inusitada em se tratando de uma praia: a possibilidade de estacionar o veículo automotor, seja ele qual for, junto à orla. Assim, os carros ficam estacionados entre o cordão de dunas, e o mar, ocupando esse espaço em forma de linhas paralelas à costa, as quais ainda estabelecem um corredor próprio para mobilidade desses veículos, permitindo a livre circulação dos mesmos durante todo o ano e, especialmente, durante o período de alta temporada em Janeiro e Fevereiro.

Podemos observar isso na Figura 1:

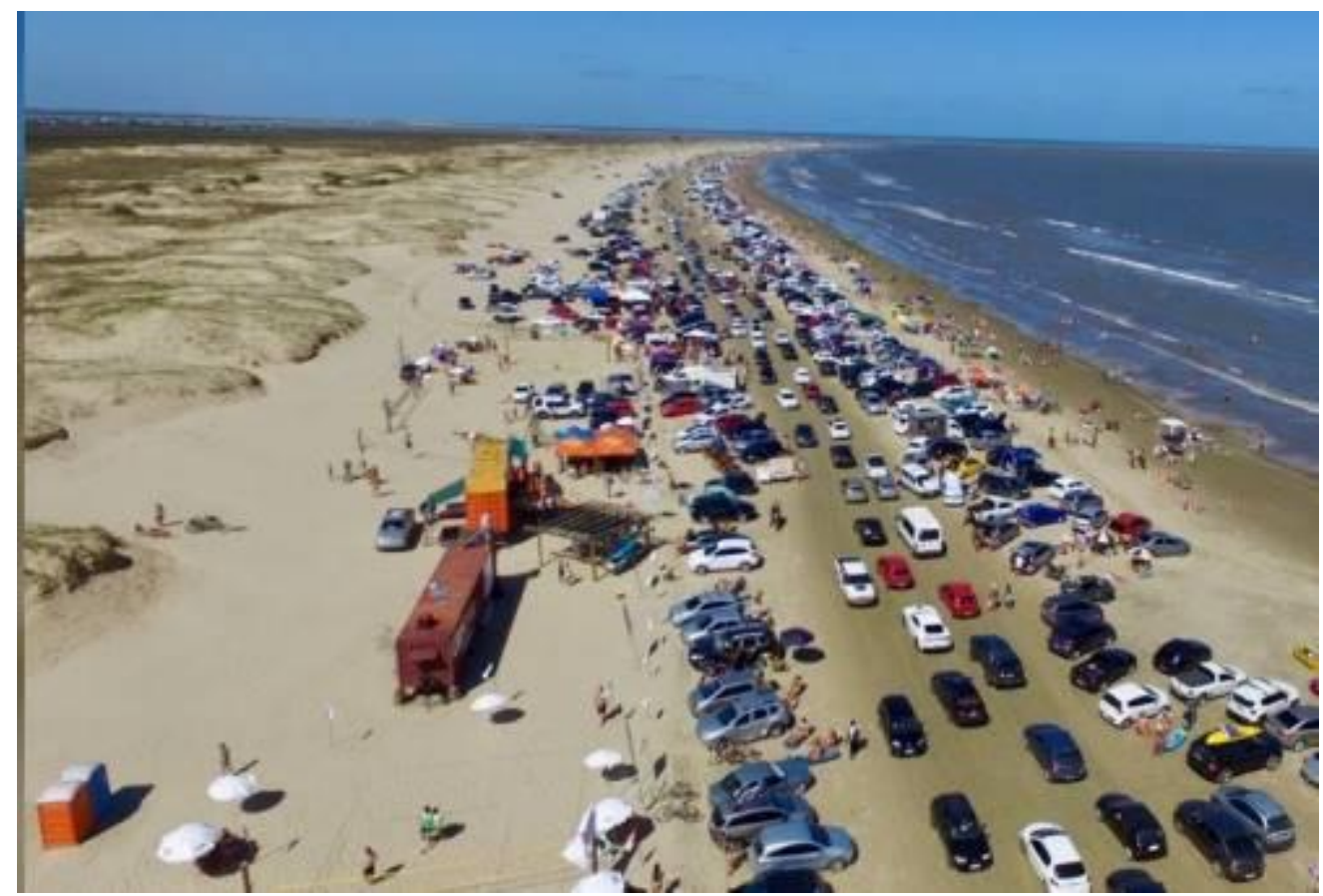

Figura 1: Carros na praia do Cassino - 2017.

Fonte: http://grupooceano.com.br.

Tal cenário, que remonta uma prática cultural de acesso ao espaço de praia que data das primeiras décadas do século $X X$, parece oferecer uma forma de lazer baseada na comodidade que ela imputa ao frequentador do Balneário Cassino. Recentemente, esse modelo de uso foi transformado em Patrimônio da Cultura Imaterial da Cidade de Rio Grande, o que ocorreu através do Projeto de Lei № 43/2017, de 02 de março de 2017 elaborado pela Câmara de Vereadores da cidade, fazendo dessa prática um elemento a ser salvaguardado pelo município.

Nesse sentido, é justamente sobre esse processo de patrimonialização da/na zona costeira, e os impactos ambientais que estão atrelados a essa salvaguarda, que o presente artigo se debruça. Ao propor uma análise qualitativa junto ao campo da Educação Ambiental (EA) da referida lei em suas 
interlocuções com as esferas federais e estaduais que legislam sobre o patrimônio natural e costeiro no território nacional, buscamos perceber, primeiro, a compreensão ecossistêmica naquilo que tange aos "sentidos do ambiental" (CARVALHO, 2002) que estão em jogo e, em seguida, apresentar os possíveis cenários de impactos junto à biodiversidade desse território.

Ao problematizar os limites dessa patrimonizalização sob o viés qualitativo, acreditamos ser possível "apreender o caráter complexo e multidimensional dos fenômenos, além de capturar os variados significados das experiências vividas no ambiente auxiliando a compreensão das relações entre as pessoas, seu contexto e suas ações" (RHEINHEIMER; GUERRA, 2009, p. 418). Tal compreensão soma-se a um esforço interpretativo que está posto no âmbito dos fundamentos da EA: a desmistificação da relação ambivalente entre natureza e cultura, relação essa que impôs uma série de binariedades historicamente localizáveis no tempo e espaço da sociedade Ocidental, como muito bem aponta Keith Thomas em sua obra $O$ homem e o mundo natural (2010), ou Carlos Walter Porto Gonçalves quando evidencia o conceito de natureza e sua condição "não natural" (GONÇALVES, 2006, p. 23).

Nessa mesma direção, a compreensão elaborada por Foladori e Taks (2004), também traça um horizonte de percepção para análises que discutem a relação natureza-cultura. Ao abordar a necessidade de um olhar antropológico para as questões ambientais, os autores destacam uma contribuição a qual chamam de esfera "informativa" que estaria ligada à desmistificação sobre a relação das sociedades com seus ambientes naturais, e também um diálogo "metodológico" que visa abordar os problemas ambientais "de modo a caminhar rumo a sociedades mais sustentáveis" (FOLADORI; TAKS, 2004, p. 323).

Para realizar esse percurso organizamos uma contextualização histórica quanto ao uso dos veículos à beira mar na praia do Cassino, e a consequente efetivação da lei que garante o estatuto de patrimônio a essa prática em suas estratégias de interlocução com a legislação do patrimônio natural costeiro vigente. Em seguida, a relação que tal patrimonialização costeira pode estabelecer, a partir de seus critérios teóricos e práticos de uso que visa efetivar junto à praia, no conjunto de impactos ecossistêmicos que poderiam afetar a biodiversidade desse local.

\section{Uma história de mar, areia e motores}

O Balneário Cassino foi fundado em 1890, sendo parte do município de Rio Grande, e integrando, assim, cerca $200 \mathrm{~km}$ da planície costeira do Rio Grande do Sul. Os primeiros registros do uso de veículos na orla datam de 1920, quando o periódico Echo do Sul evidencia a seguinte notícia:

No Casino

As corridas de 24 de fevereiro. Regulamento das corridas de automóveis em que em benefício da Sociedade Estrada de 
Rodagem do Rio Grande terão lugar no dia 24 de fevereiro de 1927 na Praia do Casino: Artigo 1 - Serão corridas as seguintes provas:

$1^{\text {a }}$ categoria - percurso de $10 \mathrm{~km}$

$2^{\text {a }}$ categoria - percurso de $20 \mathrm{~km}$

$3^{\text {a }}$ categoria - percurso de $60 \mathrm{~km}$ (ECHO DO SUL, 20 de fevereiro de 1927).

A partir desse momento será frequente encontrar imagens como essa abaixo (Figura 2), quando podemos perceber o que pode ser considerado um alinhamento veicular sendo praticado já nas primeiras décadas do século XX:

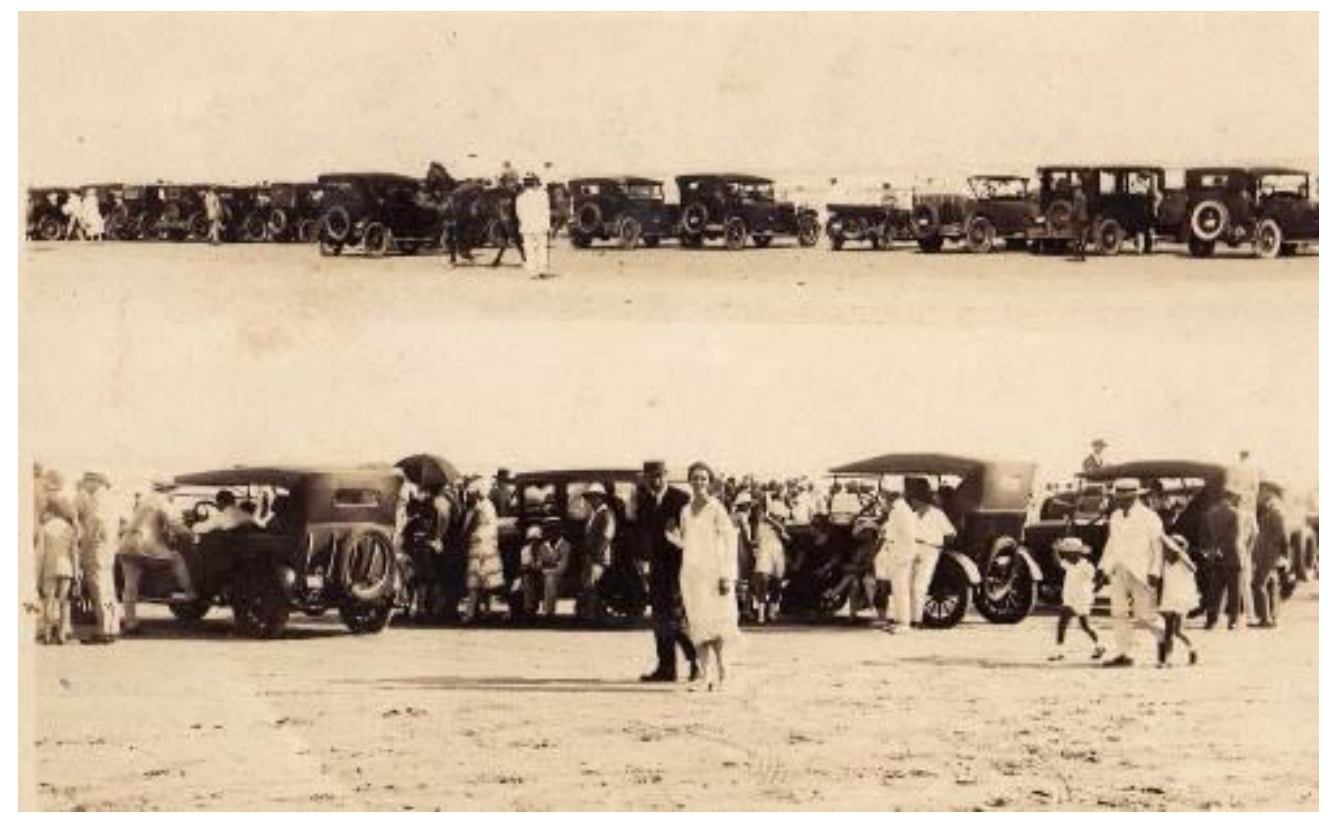

Figura 2: Visita a praia do Cassino - Década de 1930.

Fonte: Bibliotheca Rio-Grandense.

Nesse cenário, o carro se faz presente como signo da modernidade, ele representa a distinção social em jogo nesse contexto, e ao mesmo tempo se agrega ao imaginário de uma maquinaria que se conecta ao corpo, encontrando na praia uma forma de referenciar essa dupla potência cultural: a distinção e a força (SEVCENKO, 1992). Igualmente, o uso de veículos na costa permitirá uma ampliação do conhecimento e prática da paisagem litorânea, visto que torna possível o deslocamento pela orla a partir de uma mobilidade paralela ao mar e as dunas, criando mesmo uma faixa de rodagem que alarga, desde então, os limites balneares. 


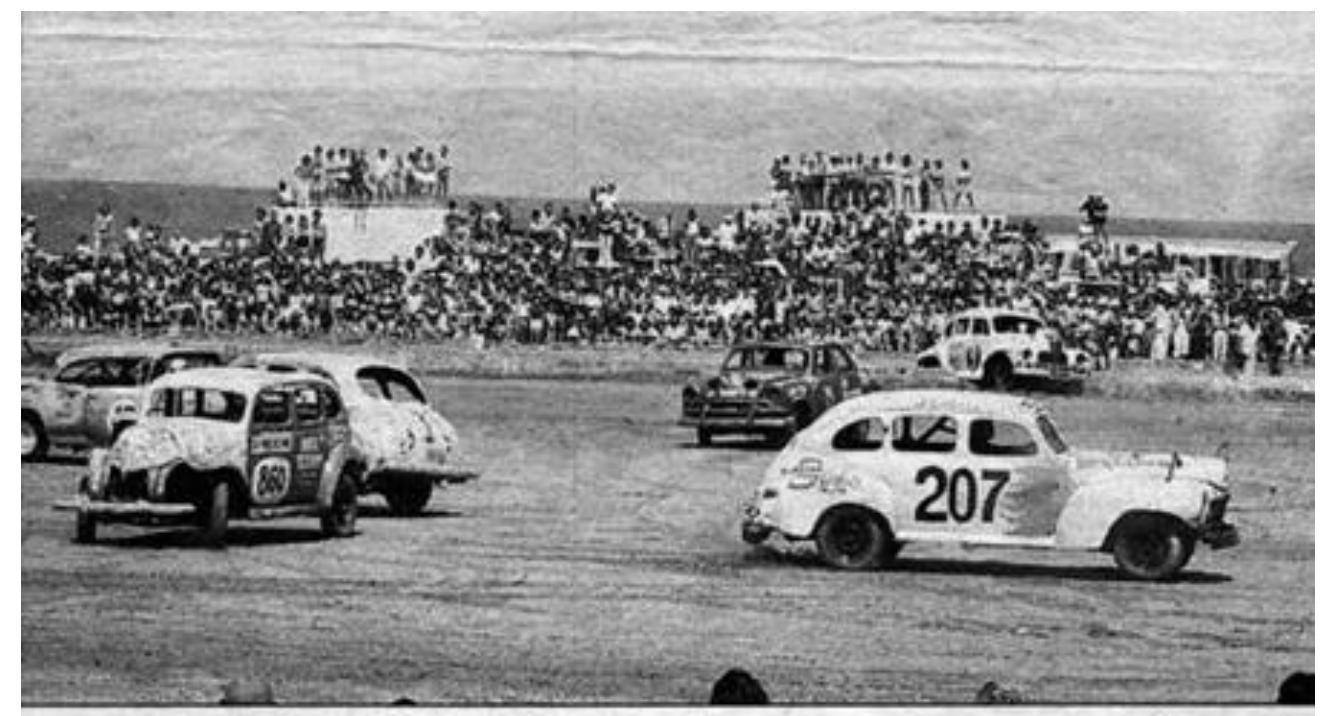

A prova de shock-car, na Praia do Cassino, em fevereiro de 1974, reuniu carnos importados como os Nash, Chrysler, Studebaker, Ford e Chevrolet

Figura 3: Competição de Shock-car na praia do Cassino - 1974.

Fonte: https://carrosantigos.wordpress.com/2010/01/01/shock-car-brasil/ .

Tal característica de praia a ser percorrida enquanto trajeto, em um constante deslocamento que não necessariamente almeja a fixação em algum de seus pontos, acentuou-se nos anos seguintes. Já na segunda metade dos novecentos a linha de praia se transformaria no estacionamento dos ônibus de excursão que chegavam de toda região, assim como palco de competições de Shock-Car que ocorriam nas areias à beira mar, quando essa passa a ser uma arena a esse tipo de esporte (FERREIRA; FREITAS, 2017).

Os anos 1980 e 1990 já apresentam um contexto em que os carros estão incorporados definitivamente à cultura dessa costa. Assim, como desdobramento da popularização dos veículos nas últimas duas décadas (PEDROSA et al., 2016), a sua presença na orla ficou ainda mais marcante como podemos perceber na imagem que utilizamos para iniciar o artigo.

Se aqui nos preocupamos em demonstrar esse lastro cultural que diz respeito ao uso de veículos nessa faixa da planície costeira do Rio Grande do Sul, é porque acreditamos, assim como Isabel Cristina de Moura Carvalho (2002), que esse tipo de atitude investigativa fornece pistas para compreender os "sentidos do ambiental" em jogo dentro de determinada sociedade, a forma como ela opera seus conceitos de natureza e cultura que estão na origem de seus processos de socioambientais (CARVALHO, 2002, p. 36). Tal movimento teórico-metodológico de base qualitativa, interpretativo, é a chave para trazer à tona o possível repertório de motivações que forneceram sentido à criação da Lei № 43/2017, de 02 de março de 2017, visto que ela se vale, justamente, dessa historicidade para legitimar-se frente ao atual debate sobre as formas de uso desse espaço. 
O projeto de lei de autoria do vereador Filipe Branco (PMDB) surge após uma série de audiências públicas ${ }^{4}$ realizadas em fevereiro de 2017 pelo executivo municipal com a comunidade costeira do Balneário Cassino, e bairros adjacentes. Tais audiências visavam debater um conjunto de regramentos sobre a orla que diziam respeito, fundamentalmente, a uma faixa de exclusão de veículos, o que era demandado pelo órgão licenciador estadual, a Fundação Estadual de Proteção Ambiental Henrique Luis Roessler (FEPAM), cabendo ao município cumprir tais condicionantes.

É nesse contexto que o edil apresenta um projeto contendo o seguinte conteúdo:

Art. 1․ Fica declarado como integrante do patrimônio cultural imaterial do Município, o "costume do uso de veículos na beira da praia do Cassino".

Art. $2^{\circ}$. O patrimônio cultural imaterial do Município declarado por esta lei,será regulado através do Plano de Zoneamento de Uso da Praia do Cassino, ordenando o uso e a ocupação da faixa de praia do Balneário Cassino (PROJETO DE LEI № 43/2017, 02 DE MARÇO, 2017).

Ainda nesse texto legislativo, o projeto de lei apresenta o que chama de "Justificativa", momento em que elenca uma série de fatores que corroborariam com o intento de salvaguarda de veículos na beira mar. É nesse momento que a Constituição Federal, em seus artigos 215 e 216, surge para categorizar os bens patrimoniais de natureza material e imaterial, naquilo que tange "os modos de criar, fazer e viver dos grupos formadores da sociedade brasileira" (PROJETO DE LEI № 43/2017, 02 DE MARÇO, 2017). Da mesma forma, para conceituar o que seria a salvaguarda dos patrimônios culturais imateriais o vereador recorre às acepções da UNESCO, que define como patrimônio imaterial:

as práticas, representações, expressões, conhecimentos e técnicas - junto com os instrumentos, objetos, artefatos e lugares culturais que lhes são associados - que as comunidades, os grupos e, em alguns casos, os indivíduos reconhecem como parte integrante da cultura material (PROJETO DE LEI № 43/2017, 02 DE MARÇO, 2017).

${ }^{4}$ http://g1.globo.com/rs/rio-grande-do-sul/jornal-do-almoco/videos/t/rio-grande/v/audiencia-publica-debatecirculacao-de-carros-na-praia-do-cassino-em-rio-grande-rs/5702717/

Revbea, São Paulo, V. 14, № 1: 245-262, 2019. 
imaterial se faz necessário no caso da praia do Cassino, já que estaria conectado a um saber, modo de fazer, a uma forma de expressão e baseada nos costumes e tradição (PROJETO DE LEI № 43/2017, 02 DE MARÇO, 2017). Diz ainda:

o costume centenário dos moradores rio-grandinos, veranistas e visitantes do Balneário Cassino, é acessarem a praia utilizando veículos (automotores ou não) e estacionarem a beira mar para desfrutarem do sol e dos banhos de mar (PROJETO DE LEI № 43/2017, 02 DE MARÇO, 2017).

O vereador encerra 0 texto legislativo utilizando a expressão "IMPORTANTE", sendo tal palavra evidenciada em letras maiúsculas e marcadas por um grifo parece querer nos informar com ainda mais afinco que:

Tal fato não só salvaguardaria um COSTUME (grifo do documento) ameaçado com sua aprovação e regulamentação enquanto um produto protegido, fomentar sua revitalização entre os moradores, rio-grandinos, veranistas e visitantes do Balneário Cassino, visto não serem mais passível de serem enquadrados como prática ilegal (PROJETO DE LEI № 43/2017, 02 DE MARÇO, 2017).

No formato de uma recomendação final, encontramos a seguinte passagem: "Recomenda-se, ainda, que ações de regulação se enquadrem no Plano de Zoneamento de Uso da Praia do Cassino, ordenando o uso e a ocupação da faixa de praia do Balneário Cassino" (PROJETO DE LEI No 43/2017, 02 DE MARÇO, 2017). Esse plano, de esfera municipal, remete diretamente a Lei 6.585 , de 20 de agosto de 2008, a qual dispõe sobre as diretrizes de desenvolvimento urbano junto ao Plano Diretor Participativo, e contempla, em algumas passagens, o que pode ser encarado como um ordenamento do uso da orla, bem como versa sobre questões de mobilidade urbana nesse espaço em seu artigo 53.

O projeto de lei, após aprovado pela Câmara Municipal em 26 de abril de 2017, com 11 votos favoráveis, foi para sanção do prefeito, que o vetou. Ao retornar para o legislativo, o veto foi derrubado pelos vereadores em 31 de maio do mesmo ano, com 13 votos favoráveis dos 18 vereadores presentes na casa $^{5}$, entrando em vigor, assim, a lei que aqui acabamos de apresentar.

O primeiro item que deve ser trazido à tona na análise dessa lei diz respeito ao fato dela ir à contramão da legislação estadual vigente desde 1991 que versa, especificamente, sobre o uso de veículos nas praias:

${ }^{5}$ http://www.camara.riogrande.rs.gov.br/index.php?h sistema $=3088$ \&id noticia $=782 \&$ id vereador $=\mathrm{NTg}=\underline{\mathrm{htt}}$ p://www.camara.riogrande.rs.gov.br/index.php? $n$ sistema $=3088 \&$ id noticia $=796 \&$ id vereador $=\mathrm{NTg}=$ 
Art. $1^{\circ}$ - Nas áreas de praias balneárias, destinadas ao descanso, aos desportos, à recreação e ao lazer em geral, cuja demarcação é imposta aos municípios pela LEI № 8.676, de 14 de julho de 1988, fica proibida a circulação de veículos, devendo a autoridade municipal, que sobre elas detém a jurisdição, manter a correspondente sinalização (LEI ESTADUAL № 9.204 DE 11 DE JANEIRO DE 1991).

Porém, essa pode ser encarada como o primeiro dos elementos, e talvez o mais evidente por se tratar exatamente de um dispositivo estadual imediato sobre o assunto, mas outras observações relativas às apropriações realizadas no que tange à legislação costeira e patrimonial merecem ainda ser feitas. $\mathrm{E}$ aqui começamos por uma caracterização no âmbito do artigo 225 da Constituição Federal de 1988, quando se considera a Zona Costeira como patrimônio nacional, "e sua utilização farse-á, na forma da lei, dentro das condições que assegurem a preservação do meio ambiente, inclusive quando ao uso dos recursos naturais" (BRASIL, Art. 225, 1988).

Nesse sentido, podemos dizer que está na Lei 7.661, de 16 de maio de 1988 a apresentação do primeiro conjunto de políticas públicas que versam sobre a gestão da costa brasileira, as quais estariam amparadas junto ao Plano Nacional de Gerenciamento Costeiro (PNGC). Será nesse documento que encontraremos a instituição de políticas que visam à conservação e proteção dos bens naturais e culturais presentes na zona costeira brasileira, como é o caso dos sítios arqueológicos e, especificamente: "monumentos que integrem o patrimônio natural, histórico, paleontológico, espeleológico, arqueológico, étnico, cultural e paisagístico" (PLANO NACIONAL DE GERENCIAMENTO COSTERO, LEI 7.661, DE 16 DE MAIO, 1988).

Está claro que, ao ser considerada patrimônio nacional natural, a zona costeira passa ser um território a ser salvaguardado com políticas que visem a sua conservação. O que está em jogo é a noção de preservação dessas áreas, por consequência, do ecossistema costeiro dentro sua biodiversidade que assegure o que a própria Constituição aponta ao falar sobre o direito a um meio ambiente ecologicamente equilibrado.

Nesse sentido, o PNGC surge enquanto instrumento de gestão dessas prerrogativas de salvaguarda, e com isso reafirma valores que apontam para a mesma condição preservacionista da costa brasileira. $O$ documento aponta para a possibilidade de patrimonialização do que chama de "monumentos" que se integrem a esse espaço litorâneo, tanto na ordem material, como imaterial, porém não abre mão de que tais elementos estejam amparados junto aos conceitos de preservação e proteção que regem essa normatização.

Se nos atentarmos para o universo conceitual mobilizado para a instituição da lei que dá o valor de Patrimônio da Cultura Imaterial para os veículos na praia do Cassino, será possível perceber que o texto se vale de interpretações oriundas da UNESCO, as quais servem de orientação para políticas patrimoniais internacionais, e não seria diferente no caso brasileiro. As Revbea, São Paulo, V. 14, № 1: 245-262, 2019. 
orientações presentes junto ao Instituto do Patrimônio Histórico e Artístico Nacional apontam para o seguinte horizonte:

O patrimônio imaterial é transmitido de geração a geração, constantemente recriado pelas comunidades e grupos em função de seu ambiente, de sua interação com a natureza e de sua história, gerando um sentimento de identidade $e$ continuidade, contribuindo para promover o respeito à diversidade cultural e à criatividade humana (INSTITUTO DO PATRIMÔNIO HISTÓRICO E ARTÍSTICO NACIONAL ${ }^{6}$ ).

Existe, como se pode observar, a relação das práticas culturais concatenadas a sua função com o "ambiente", e suas interações com a natureza. Se nos voltarmos para os preceitos da legislação sobre o patrimônio nacional natural, mais uma vez lembramos que o norte da salvaguarda deve obedecer aos preceitos de preservação e proteção dos recursos naturais, o que deve valer para os casos que dizem respeito à patrimonialização da cultura imaterial.

São essas categorias que estão sendo acionadas pela legislação municipal de salvaguarda do uso de veículos na linha de costa, as quais circunscrevem uma argumentação que se vale da prática histórica para legitimar a iniciativa e, da mesma forma, contornar a legislação já existente que torna essa mesma prática ilegal. A questão que se impõe ao observar as premissas patrimoniais para a zona costeira, e que parece ser omitido pelo texto final do projeto de lei, diz respeito à orientação do documento em "fomentar a revitalização" da prática do uso de veículos na praia do Cassino, já que seria esse um "costume".

Seria esse um ponto passivo de discussão se não estivéssemos falando de veículos automotores que podem provocar a degradação da própria linha de costa em sua biodiversidade ecossistêmica. Contrariando a legislação vigente, e estabelecendo justificativas que parecem obedecer a uma condição bastante maleável daquilo que viria a ser uma apropriação capaz de provocar impactos ambientais desse território, o texto da lei acaba por não considerar os possíveis desequilíbrios ambientais que estarão presentes com tal fomento.

Com isso, a lei que acabou por ser sancionada é apenas a ponta do iceberg, para utilizar uma metáfora bastante ilustrativa de algo que já estava em curso, de algo que diz respeito à forma como os sujeitos se apropriaram dessa costa ao longo das décadas, permitindo, nesse ato investigativo interpretativo, perceber a construção dos "sentidos do ambiental" (CARVALHO, 2002), e a instituição de um conceito de natureza em dada sociedade. Nesse caso, a relação que transforma o recurso natural em bem de consumo a ser adaptado pelos interesses humanos, que se inscreve, no nosso caso, na

\footnotetext{
${ }^{6}$ http://portal.jphan.gov.br/pagina/detalhes/234. Acessado em 20 de junho de 2018.
} 
omissão orientada de alguns elementos que envolvem a prática do uso de carros na praia.

Se antes não havia a discussão, ou mesmo debates que pudessem posicionar-se criticamente frente a essa prática, o mesmo não pode ser dito sobre o presente momento. Por isso, é preciso estar atento para não cometer anacronismos ao criticar antigas formas de apropriação da praia e as contradições que remeteriam a problemáticas ambientais, como é o caso dos veículos na década de 1930, ou mesmo anos 1980, quando os movimentos ambientais ainda não estavam amplamente consolidados, e o debate ambiental se fazia presente de forma escassa no âmbito das políticas públicas, não havendo o que Gonçalves (2012, p. 23) chama de uma "questão ambiental" posta na sociedade.

Porém, hoje, o cenário é outro, e o que esperamos é construir um debate reflexivo junto ao campo da EA que seja capaz de projetar uma forma de repensar essa prática a partir dos dados que atualmente temos sobre as consequências da continuidade do uso de veículos na orla.

Assim, chegamos ao segundo momento desse artigo, quando visamos apresentar um painel dos riscos que estão em jogo caso seja realizado qualquer tipo de fomento a esse "costume" agora patrimonializado pelo poder municipal. Da mesma forma que elaboramos algumas contribuições às discussões envolvendo a patrimonialização costeira.

\section{Impactos na costa: os limites de uma "interpretação errônea"}

A primeira questão a ser levantada diz respeito a uma condição básica: mesmo a lei sendo sancionada dentro do status de "imaterial", o carro, o veículo automotor, é um item material. Ele existe fisicamente, ele está na linha de praia estacionado ou em circulação, estando em constante impacto com a natureza ali presente, justamente, pela sua materialidade.

Começar por esse item, que parece tão básico pontua uma discussão que já existe academicamente sobre o tema do uso de veículos na praia do Cassino. Isso porque ela se conjuga ao argumento de VIEIRA et al::

A praia do Cassino, localizada na Costa sul-rio-grandense apresenta, provavelmente, uma das faixas de praia mais impactadas pelo trânsito de veículos no mundo. Fatores históricos, culturais, geomorfológicos e uma interpretação errônea permitem o trânsito de veículos de qualquer tipo sem qualquer restrição (VIEIRA et al., 2004, p. 55). 
verdade, tal "interpretação" não é um dado aleatório, mas sim parte de uma cultura como descrevemos no item anterior, o que demonstra uma forma dos sujeitos projetarem os sentidos ambientais que perpassam tal situação.

Por isso, buscando operar um arranjo nos termos pensados por Foladori e Taks (2004), o diálogo que esses realizam com Marshall Sahlins aqui também pode oferecer significativa contribuição quando 0 antropólogo compreende que "a cultura é historicamente reproduzida na ação" (SHALINS, 2003, p. 7). E, mais adiante, diz: "sabe-se que os homens criativamente repensam seus esquemas convencionais. É nesses termos que a cultura é alterada historicamente na ação" (SAHLINS, 2003, p. 7).

O que chama atenção em tais premissas é a possibilidade da transformação de sentidos no que tange o universo da cultura, sendo possível ocorrer o que ele chama de "mudança sistêmica" (SAHLINS, 2003). É assim que compreendemos, igualmente, o debate que cerca o tema do uso de veículos na praia do Cassino. Ao discutir uma lei que patrimonializa o ambiente natural costeiro de uma forma autofágica, na qual normatiza juridicamente uma prática que colabora para a degradação do espaço em que ela ocorre, estamos projetando um outro horizonte interpretativo a esse objeto da cultura, inserindoo em outro debate, agora no campo da EA, e que passa a ser feito não nos termos de legitimação histórica, mas sim da relação que queremos manter com essa natureza que é finita, e que todo e qualquer impacto sofrido possui, invariavelmente, consequências maiores que vão para muito além da zona costeira.

Daí a importância de apresentar dados como esses de Vieira et al. (2004), que argumentam em suas pesquisas que ao compactar-se a areia diminui-se o índice de vazios aumentando a resistência aos deslocamentos líquidos e gases no meio, interferindo diretamente nos processos biológicos desse ecossistema (VIEIRA et al., 2004, p. 55). Ou então os de Lopes et al. (2007), que apontam para alterações ecossistêmicas oriundas dessa prática de rodagem dos carros na praia:

Tais impactos são os responsáveis pela diminuição da população de mariscos, um bivalve muito comum nesta parte do litoral, os quais não são mais encontrados na fase adulta nas zonas de maior trânsito, também pelo desaparecimento do crustáceo Ocypode quadrata, espécie muito sensível à presença de veículos (LOPES, et al., 2007, p. 2)

Ainda, com as marés cheias, os carros acabam se aproximando das dunas, rompendo as crostas salinas, importantes nas ações anti-erosivas que viabilizam vegetações precursoras e servem de local de nidificação de aves, e abrigo para comunidades de pequenos mamíferos e roedores (LOPES, et al., 2007 , p. 2). Esses mesmos pesquisadores reconhecem a pouca repercussão de dados como esses pelo poder público local, transformando mesmo isso em

revista brasileira educação ambiental 
"atrativo desprezando a destruição do ecossistema costeiro" (LOPES, et al., 2007, p. 2).

Dados recentes, de 2016, apresentam o número de 12.824 mil carros espalhados em uma faixa de $20 \mathrm{~km}$ num dia de alta temporada - o que configura um aumento significativo em termos de impacto nos últimos anos (SOUZA; HECKTHEUR; RIGO, 2016, p. 297). Em um dia de verão, então, a praia alcança o cenário encontrado na Figura 4:

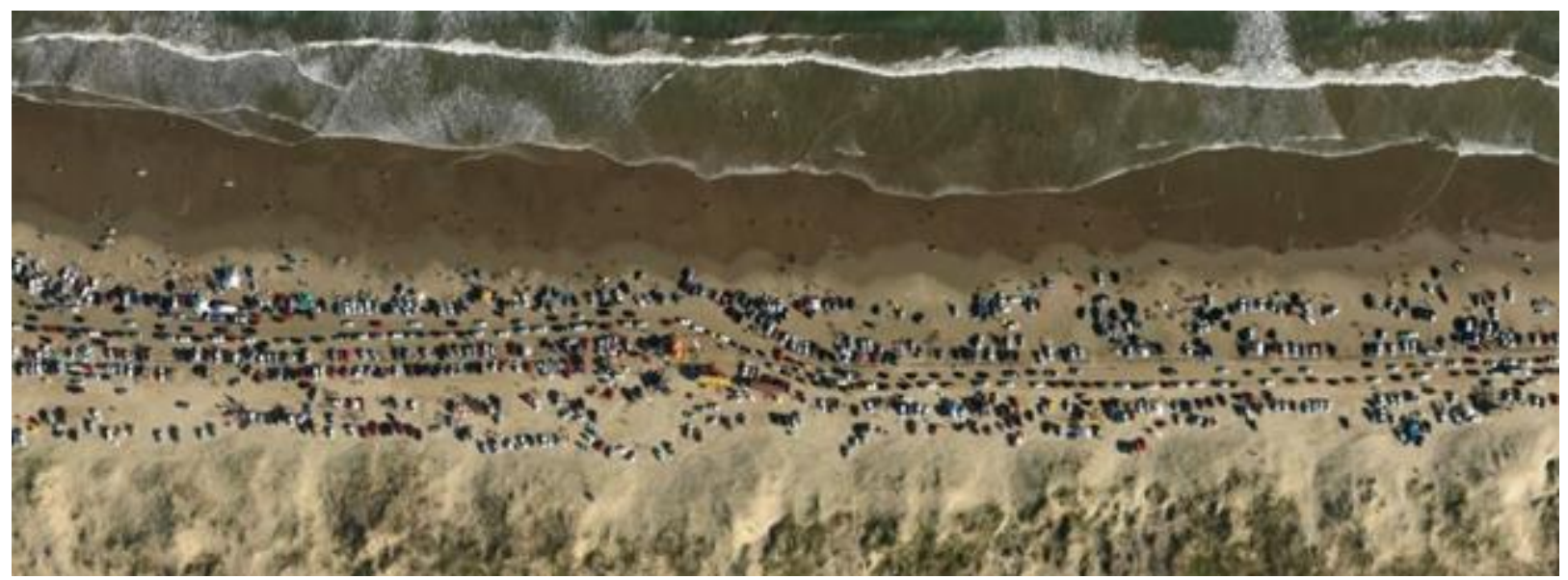

Figura 4: Vista aérea da praia - 2016.

Fonte: Registro de Glauber Gonçalves extraído de SOUZA; HECKTHEUR; RIGO, 2016.

Como se pode perceber, a formação de sete linhas de veículos em alguns trechos da orla deixa claro os impactos ambientais que estão em curso quando apontamos alguns elementos como os citados por Lopes et al. (2007) no caso do crustáceo Ocypode quadrata, ou a população de mariscos no Cassino. Ao romper com cadeias, alterar ecossistemas, a biodiversidade desse litoral passa a projetar uma sensibilidade, e suas consequências passam a apresentar-se em termos de desequilíbrio ambiental quando se trata de "fomentar a revitalização" - utilizando o termo da lei envolvido na patrimonialização em questão.

Os efeitos sobre a biota já estão sendo observados, e ainda podem se agravar quando nos atentamos que, em períodos de maré cheia, quando a linha do mar avança, os carros passam a trafegar na proximidade das dunas, rompendo as crostas salinas, as quais são "importantes na ação anti-erosiva e que viabilizam a vegetação precursora das dunas, servindo de local de nidificação de algumas aves, e abrigo para as comunidades de pequenos mamíferos e roedores" (LOPES et al., 2007, p. 2). Por isso, revitalizar uma prática que causa o rompimento da vida para inúmeros organismos vivos da zona costeiras, e que deixam de ser considerados muitas vezes pelo fato de, ainda até esse momento, estarem "ocultos na areia ou expostos ao ar apenas durante os períodos de baixa maré" (LOPES, et al., 2000), parece ser elemento intrínseco a política patrimonial costeira que foi posta em curso na cidade de Rio Grande.

Revbea, São Paulo, V. 14, № 1: 245-262, 2019. 
Dos nexos interpretativos que é possível estabelecer nessa análise, os sentidos do ambiental em jogo parecem apontar para uma omissão orientada desses dados científicos, quando o falseamento se dá na não observação holística do tipo de política que se pretende tornar pública. Nesse caso, patrimonializar surge enquanto estratégia política de manutenção de uma prática que, por muitos anos, tratou de reinventar-se até o ponto de naturalizarse, quando, na verdade, sempre foi, e hoje ainda é, parte de um repertório cultural historicamente verificável em sua criação pelos sujeitos.

E aqui é importante lembramos, utilizando a metáfora explicativa de Alain Corbin (1989, p. 266), inventa-se a praia, e nesse caso, então, inventaram-se os carros na praia. Essa dimensão precisa ser constantemente retomada, visto que traz, por exemplo, ao campo da Educação Ambiental, uma possibilidade de problematização ligada às formas engendradas pelos sujeitos quanto ao uso dos litorais para banhos a partir do século XVIII, e sua consolidação no decorrer do XIX ao redor do globo.

A escolha em apresentar esse projeto, justamente, após uma série de audiências públicas que visavam debater a adequação da licença da orla em suas proposições relativas ao uso de carros na praia, especialmente a sua exclusão em um trecho inicialmente de $800 \mathrm{~m}$, não pode deixar de ser percebido, também, como um ato político em curso - que parte de uma representatividade legitimada, e que atende a interesses diferentes daqueles do órgão licenciador, e das pesquisas científicas que aqui apresentamos. $E$ com isso não podemos esquecer a dimensão política que José Reginaldo Gonçalves propõe ao patrimônio quando diz que ele é usado para simbolizar, representar, comunicar, mas também agir (GONÇALVES, 2003, p. 27).

Ao dizer que "o patrimônio, de certo modo, forma as pessoas" (GONÇALVES, 2003, p. 27) parece ser possível perceber uma interlocução direta com as formas de apropriação do ambiental pelos sujeitos. Ou seja, ao falarmos em processos de patrimonialização no ecossistema costeiro, não é possível negar a existência de uma escolha de sociedade em curso, para cada opção, para cada tomada de posição junto ao debate sobre os carros na praia do Cassino abre-se uma postura de comunidade quanto à forma como deseja se relacionar com os seus recursos naturais. .

Essa postura da sociedade com os seus patrimônios naturais perpassa uma discussão contemporânea, e que François Hartog (2006) traz à tona quando diz:

A patrimonialização do meio ambiente, que designa a extensão provavelmente mais massiva e a mais nova da noção, abre indubitavelmente sobre o futuro ou sobre novas interações entre presente e futuro (HARTOG, 2006, p. 272).

Nesse sentido, os trabalhos desenvolvidos por Silvia Helena Zanirato (2009; 2009b) confirmam o entendimento de Hartog (2006), já que a 
pesquisadora se debruça sobre o patrimônio natural e o tema das mudanças climáticas, questionando, justamente, as formas de apropriação desse debate no Brasil. Ao estarmos diante de um caso como esse, que diz respeito ao "fomento" de uso de carros no ecossistema costeiro, surgiria, também, uma questão que se vincula, por exemplo, ao incremento da emissão de gases tóxicos na atmosfera.

Ao trazer à tona os usos sociais do patrimônio natural conectados a questão das alterações ambientais globais, e por consequência as políticas de patrimonialização, a pesquisadora chama atenção para a "mercantilização da natureza" (ZANIRATO, 2009, p. 139) que estaria em curso nas últimas décadas. Tal postura ameaça diretamente o patrimônio natural no entendimento da autora, sendo que a sua manutenção ocorre tanto na forma como as iniciativas de salvaguarda se processam politicamente, orientandas por um desconhecimento e pouco interesse em saberes científicos, como também pelo pouco acesso da participação pública no que tange as formas de proteção dos bens naturais em um diálogo horizontalizado e capaz de expor o conjunto de complexidades envolvidas nesses casos (ZANIRATO, 2009).

Reconhecendo a importância da Educação Ambiental, Silvia Zanirato (2009) já aponta a relevância do trabalho com a noção do pertencimento coletivo para a superação desse cenário. Da mesma forma, projetos de Educação Patrimonial ligados aos recursos naturais seriam de fundamental importância para que pudéssemos iniciar um novo tipo de debate sobre o tema.

E será aliado a essa compreensão que acrescentamos, também, a inserção da noção de risco, mais precisamente, de risco ambiental junto aos processos de patrimonialização em ambientes costeiros. Mesmo que já exista uma orientação que pode ser percebida nos documentos que aqui apresentamos, quando pensamos, por exemplo, o Artigo 225 da Constituição Federal, a obrigatoriedade da vinculação de um estudo de risco ambiental junto ao devido processo legal da demanda patrimonial poderia colaborar para que novas contradições desse tipo não entrassem em curso.

Tal iniciativa, que aqui se mostra como resultado de uma primeira reflexão baseada no estudo de caso da praia do Cassino reconhece a emergência de trabalhos que tratam da categoria "risco ambiental" (KUHNEN, 2009; BECK, 2011; ROSA et al., 2015), e passa a pensar a partir daí uma intervenção que possa se dar por dentro da política pública, e também por outra postura de diálogo social sobre o tema. Daí o papel estratégico de uma discussão patrimonial que reconheça uma aproximação necessária com a Educação Ambiental, a qual pode colaborar como campo do conhecimento aglutinador dessa nova postura ética no que tange a relação da sociedade com a natureza.

Pois, afinal, parece ser isso que também percorre todo o debate que aqui propomos quando evidenciamos esses sujeitos que, ao longo do tempo, através de suas práticas, consolidaram uma postura que se distanciava do próprio ecossistema, transformando o mundo em objeto. Essa é uma 
perspectiva que Mauro Grün, em uma passagem de sua obra Ética e Educação Ambiental - a conexão necessária (1996), explicita quando fala da constituição de uma racionalidade cartesiana em que "o sujeito autônomo está fora da natureza" (GRÜN, 1996, p. 44).

A mudança desse cenário exigiria, portanto, passarmos a pensar a partir de uma crítica permanente aos processos de objetificação promovidos e sustentados por uma ética antropocêntrica que se mostra altamente nociva quando desconsidera a presença do sujeito no meio, enquanto parte, e não centro, de todo e qualquer ecossistema (GRUN, 1996, p. 51). Ao mesmo tempo, refletir sobre as possibilidades de transformação, ou pelo menos de tensionamento dessa postura que parece vigorar na sociedade atual, e que se faz presente também em ações de patrimonialização, é parte do esforço que deve ser feito para um horizonte ecologicamente mais harmonioso entre os sujeitos e o meio em que vivem.

\title{
Conclusões
}

Em uma passagem de sua obra A beira mar (2010), publicado em 1955, Rachel Carson diz:

\begin{abstract}
Nas areias da orla marítima, especialmente onde elas são largas e limitadas por contínuas de dunas produzidas pelo vento, há uma percepção de como são antigos esses locais (...) A areia é uma substância fascinante, misteriosa e infinitamente variável; cada grão na praia é o resultado de processos que remontam aos obscuros primórdios da vida, ou mesmo da própria Terra (CARSON, 2010, p. 120).
\end{abstract}

Essa descrição tão interessante que Carson consegue fazer de da orla da praia, da perspectiva da sua porção terrestre, da areia que é percebida enquanto um organismo capaz de contar em si tanta história quanto qualquer outro ser vivo que habite o ecossistema, parece se conectar diretamente com a forma como propomos passa a olhar sobre tema da utilização dos carros na praia sob o viés da Educação Ambiental.

Ao invés de uma linearidade antropocêntrica preocupada em apontar culpados por práticas pretéritas, o nosso interesse se concentrou em perceber historicamente uma prática e a tecer dentro de outro panorama. Se antes não havia uma "questão ambiental" (GONÇALVES, 2012), hoje não há dúvidas que ela existe, por isso a necessidade em tecer uma problematização que esteja alicerçada não mais em uma diferenciação entre natureza e cultura, mas sim repensada em termos paradigmáticos, que seja capaz de projetar uma nova postura ambiental junto à experiência dos sujeitos no ambiente.

A capacidade de perceber que o uso contínuo de veículos na orla da praia leva à degradação do ecossistema a partir de um conjunto de impactos ambientais é um movimento em que a EA se coloca como essencial na busca 
por outros entendimentos, e práticas quanto à forma com que os sujeitos se relacionam na situação experiencial com o meio ambiente. Assim, a compreensão das inflexões ambientais contemporâneas alcançaria, também, uma mudança nos termos das políticas públicas ligadas ao patrimônio natural, alcançando o plano legislativo e executivo em seu horizonte de intervenção social da tomada de decisão até a efetivação de seus projetos dentro de outro modelo ético não predatório e baseado em uma relação de posse com a natureza.

\section{Agradecimentos}

A Coordenação de Aperfeiçoamento de Pessoal de Nível Superior (CAPES), pelo apoio financeiro à pesquisa; à Universidade Federal do Rio Grande (FURG), por tornar possível o doutoramento do autor, assim como ao grupo de pesquisa Ribombo vinculado ao CNPq.

\section{Referências}

BECK, U. Sociedade de Risco - rumo a uma outra modernidade. São Paulo, Editora 34, 2011.

BRASIL. Constituição (1988). Constituição da República Federativa do Brasil. Brasília, DF: Senado Federal: Centro Gráfico, 1988. 292 p.

BRASIL. Lei n. 7.661, de 16 de maio de 1988, que institui o Plano Nacional de Gerenciamento Costeiro - PNGC, Brasília, 1988.

CARSON, R. Beira Mar. São Paulo, Gaia, 2010.

CARVALHO, I.C.M. A invenção do sujeito ecológico - narrativas e trajetórias da Educação Ambiental no Brasil. 2 $2^{\underline{a}}$ ed, Porto Alegre, Editora da UFRGS, 2002.

ECHO DO SUL, Rio Grande, 20 de fevereiro de 1927. Acervo da Bibliotheca Rio-Grandense.

FERREIRA, F.N.; FREITAS, J. V. Mar, areia e sensibilidade ambiental: primeiros apontamentos sobre a invenção da paisagem na Praia do Cassino Rio Grande (RS). Revista Brasileira de Educação Ambiental (REVBEA), São Paulo, Vol. 12, n. 4: 88-103, 2017.

FOLADORI, G.; TAKS, J. Um olhar antropológico sobre a questão ambiental. Mana, n. 10 (2), 2004, p. 323-348.

GONÇALVES, J.R. O Patrimônio enquanto uma categoria do pensamento. In: CHAGAS, Mario (Org). Memória e Patrimônio: ensaios contemporâneos. Rio de Janeiro, DP\&A, 2003

GONÇALVES, C.W.P. Os (des)caminhos do Meio Ambiente. $14^{\circ}$ ed. São Paulo, Contexto, 2006. 
GONÇALVES, C.W.P. O desafio ambiental. $3^{\underline{a}}$ Ed. Rio de Janeiro, Record, 2012.

GRÜN, M. Ética e Educação Ambiental: a conexão necessária. São Paulo, Papirus Editora, 1996.

HARTOG, F. Tempo e patrimônio. Varia Historia. Belo Horizonte, vol. 22, no 36, Jul/Dez 2006, p. 261-273.

KUHNEN, A. Meio Ambiente e Vulnerabilidade: a percepção ambiental de risco e o comportamento humano. Geografia (Londrina). Vol. 18, n. 2, 2009. p. 3752

LOPES, M.N; CHAVES, P; SAN MARTIN, L; VIEIRA, H. Estudo do impacto ambiental sobre a biodiversidade da praia do Cassino causado por veículos automotores. Caxambu, Anais do VII Congresso de Ecologia do Brasil, 2007.

PEDROSA, J.G. et al. Automobilidade e (in)sustentabilidade: distorções produzidas no princípio da sustentabilidade pela indústria automobilística. Revista Eletrônica do Mestrado em Educação Ambiental. Vol. 33, n. 3, p. 281-301, set/dez, 2016.

RHEINHEIMER, C.G.; GUERRA, T. Processo Grupal, Pesquisa-açãoparticipativa e Educação Ambiental: uma parceria que deu certo. Revista Eletrônica do Mestrado em Educação Ambiental. Vol. 22, Jan/Jul, 2009, p. 417-438.

RIO GRANDE DO SUL. LEI 9.204 DE 11 DE JANEIRO DE 1991. Disponível em: http://www.al.rs.gov.br/legis/M010/M0100099.ASP?Hid Tipo=TEXTO\&Hid TodasNormas $=17505 \&$ hTexto $=\&$ Hid IDNorma $=17505$. Acessado em 18 de Jun. 2017

RIO GRANDE. LEI № 6585, DE 2º DE AGOSTO DE 2008. Disponível em: https://leismunicipais.com.br/plano-diretor-rio-grande-rs Acessado em 18 de Jun. 2017

RIO GRANDE. PROJETO DE LEI № 43/2017, 02 DE MARÇO, 2017. Disponível em: http://filipebranco.com.br/wp-content/uploads/2017/05/PL-43.pdf. Acessado em 18 de Jun. 2017

ROSA, T.S et al. A educação Ambiental como estratégia para a redução de riscos socioambientais. Ambiente e Sociedade. São Paulo, Vol. XVIII, n. 3, julset, 2015. p. 211-230.

SAHLINS, M. Ilhas de História. Rio de Janeiro, Jorge Zahar, 2003.

SEVCENKO, N. Orfeu Extático na Metrópole - São Paulo Sociedade e Cultura nos frementes anos 20. Cia das letras, São Paulo, 1992.

SOUZA, T.S.; HECKTHEUER, L.F.; RIGO, L.C. O espaço da beira da praia, a criança e a produção de uma ordem: implicações para além da escola. Revista do Programa de Pós-Graduação Interdisciplinar em Estudos do Lazer/UFMG. Vol. 19, n. 2, 2016. p. 294-328. 
THOMAS, K. O homem e o mundo natural: Mudanças de atitude em relação às plantas e aos animais (1500-1800). São Paulo, Companhia das Letras, 2010.

VIEIRA, H.; CALLIARI, L.; OLIVEIRA, G. O estudo do impacto da circulação de veículos em praias arenosas através de parâmetros físicos: um estudo de caso. ENGEVISTA, Vol. 6, n. 3, dezembro, 2004. p. 54-63.

ZANIATO, S.H. Usos sociais do patrimônio cultural e natural. Patrimônio e Memória. São Paulo. V. 5, n. 1, out/2009, p. 137-152.

ZANIATO, S.H. A conservação do patrimônio natural e cultural diante das mudanças climáticas. Conservar Patrimônio. São Paulo, n. 10, 2009b. p. 6977. 